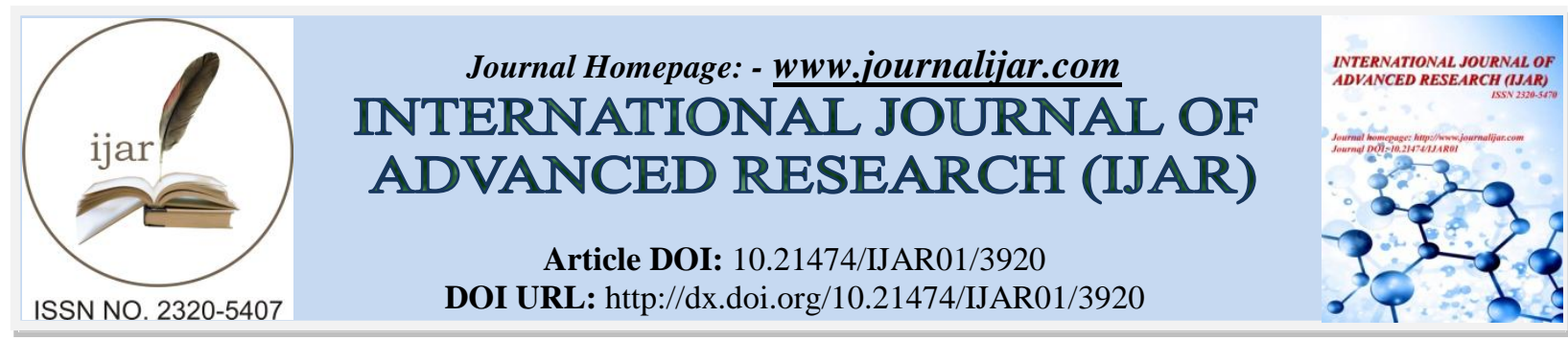

CASE REPORT

\title{
REHABILITATION OF COMPLETELY EDENTULOUS CONGENITAL CLEFT PALATE DEFECT WITH CLOSED HOLLOW BULB OBTURATOR: A CLINICAL CASE REPORT.
}

\section{"Dr. Adish Chaudhary ${ }^{1}$, Dr. Anupama Aradya ${ }^{2}$, Dr. Anil Kumar Gujjari ${ }^{3}$, Dr. Dhakshaini M. $\mathbf{R}^{4}$ and Dr. Raghavendraswamy K. $\mathbf{N}^{5}$.}

1. Post Graduation Student, Department of Prosthodontics Crown and bridge, JSS Dental College and Hospital, A Constituent College of Jagadguru Sri Shivarathreeshwara University, SS Nagara, Mysuru- 570015, Karnataka, India.

2. Senior Lecturer, Department of Prosthodontics Crown and bridge, JSS Dental College and Hospital, A Constituent College of Jagadguru Sri Shivarathreeshwara University, SS Nagara, Mysuru- 570015, Karnataka, India.

3. Principal and Professor, Department of Prosthodontics Crown and bridge, JSS Dental College and Hospital, A Constituent College of Jagadguru Sri Shivarathreeshwara University, SS Nagara, Mysuru- 570015, Karnataka, India.

4. Professor and Head, Department of Prosthodontics Crown and bridge, JSS Dental College and Hospital, A Constituent College of Jagadguru Sri Shivarathreeshwara University, SS Nagara, Mysuru- 570015, Karnataka, India.

5. Professor, Department of Prosthodontics Crown and bridge, JSS Dental College and Hospital, A Constituent College of Jagadguru Sri Shivarathreeshwara University, SS Nagara, Mysuru- 570015, Karnataka, India.

\section{Manuscript Info}

\section{Manuscript History}

Received: 14 February 2017

Final Accepted: 11 March 2017

Published: April 2017

Key words:-

Maxillofacial defects, Palatopharyngeal insufficiencies, Cleft palate, Closed hollow bulb obturator

\begin{abstract}
Rehabilitation of congenital cleft palate defect improves the quality of life for the patient as normal as possible. The successful rehabilitation of such kind of patient requires the team effort of health professionals. It is a challenging task for the prosthodontist to treat such patients. In Velopharyngeal defect, hypernasality, regurgitation of food and liquids are the common consequences if left untreated. A maxillary hollow bulb obturator was fabricated to prevent fluid leakage through nose, to maintain cleanliness, speech resonance, to improve physical and psychological health and mastication. Obturators are used to close or seal these defects to restore proper mastication, speech, deglutition, and esthetics. obturator size depends on defect's size and volume. The prosthesis should be easy to handle, simple to maintain, biocompatible, light in weight and conventional for future adjustments. This case report describes a completely edentulous cleft palate patient, which was rehabilitated with a maxillary hollow bulb obturator.
\end{abstract}

Copy Right, IJAR, 2017,. All rights reserved.

Introduction:-Cleft lip or palate is one of the most common congenital anomalies, but prevention of this malformation remains obscure. Treatment is dictated by the severity of the problem. A multidisciplinary approach is Essential to achieve optimum results. Definitive prosthodontic treatment is usually one of the final therapies iinstituted.

Corresponding Author:- Dr. Adish Chaudhary. 
Velopharyngeal deficits may result from congenital malformations. One such deficit is palatal insufficiency i.e. inadequate length of the hard and/or soft palate to affect velopharyngeal closure, but with movement of the remaining tissues within normal physiological limits that may result in hypernasality and decreased intelligibility of speech. ( Beumer J,1996).

In many patients, velopharyngeal function can be restored by surgical reconstruction. However, residual palatal deficiencies may remain after surgical treatment, which would necessitate placement of an obturator prosthesis and even selected cleft palate patients with gross deficiencies of palatal tissues are best treated prosthodontically, without surgical intervention.

The purpose of this report was to show the rehabilitation of completely edentulous patient with palatal insufficiency prosthodontically with a closed hollow bulb obturator and a description of a simple technique for the fabrication of closed hollow bulb obturator prosthesis.

\section{Case Report:-}

A 60 year-old female patient reported to Department of Prosthodontics, Crown \& bridge, JSS Dental College, a Constituent College of Jagadguru Sri Shivarathreeshwara University, Mysuru with a chief complaint of inability to chew. General Physical examination did not reveal any abnormalities and on oral examination there was completely edentulous arches with repaired cleft lip, nasal twang in her voice lacking resonance. Intraoral examination revealed a completely edentulous state with a Veau's class II defect i.e. a defect of soft and hard palate (Stewart KL 1997). The inferior chonchae were visible through the defect ( Figure 2) Tissue undercuts were present in the palatal region at the site of the defect.

Clinical evaluation showed that the oronasal communication was present since birth and she didn't undergone for any surgical treatment as she was unaware of the procedure. She underwent for cleft lip surgery at age of 8 months in a private hospital.

Considering her socio-economic condition and her functional and esthetic requirements, a closed hollow bulb obturator was planned for the patient.

A gauze strip soaked with povidine iodine solution was packed into the alveolar cleft area prior to impression making to prevent the impression material from being forced into the nasal cavity. A preliminary irreversible hydrocolloid impression ( Algitex, DPI ) was made in a stock perforated metal tray after having modified the tray with impression compound ( DPI Pinnacle)( Figure 3)The lower edentulous ridge was recorded with impression compound (DPI Pinnacle).(Figure 4)

The impressions were poured with dental stone (Kalabhai Karson pvt. Ltd.) to obtain primary casts. The blockout is done for the undesired undercuts and custom trays of auto polymerizing resin with a $2 \mathrm{~mm}$ wax spacer were fabricated over the primary casts. A u shaped wire loop is made and attached with autopolymerising resin to record pharyngeal part of the palate.(Figure 5)The tray extensions were then adjusted in the patient's mouth and border molding was done using low-fusing compound ( DPI Pinnacle Tracing sticks). In the pharyngeal region of obturator low fusing compound is added and ask the patient move the head towards right and left to touch the shoulder with chin.

The obturator portion was moulded by extend her head as far forward and backward as possible, making the patient move her head in a circular manner from side to side and to say 'ah' and swallow.

The border molding was continued till the position and contours of the obturator were satisfactory and a complete peripheral seal was obtained. The patient was able to speak, swallow and breathe through the nostrils effectively. Lower border molding was done following the routine technique.

Final impressions were made with Light body polyvinyl siloxane impression material (Ivoclar Vivadent Light body regular set) (Figure 6). Master casts with die stone (Kalstone) were then obtained. (Figure 7). Following this, Undercuts on maxillary cast were blocked out with modelling wax (Hindustan modelling wax no. 2 HDP) and autopolymerising resin was adapted over the master casts to serve as temporary record bases over which wax occlusal rims were fabricated. 
Tentative Jaw relations were recorded using the static method. Following this, face bow transfer was done and transferred to a semiadjustable articulator (Hanau wide view) (Figure 8). Artificial teeth arrangement was done (Figure 9). Following the trial, the denture was waxed-up. The denture was then flasked and dewaxing was performed. Following this, seperating medium was applied and Packing was done with heat polymerized Lucitone denture base ( Trevalon, Dentsply). To make a obturator portion hollow, Lost salt Technique was followed. one layer of heat polymerized acrylic is adapted in bulb portion and then table salt was filled upto palatal plane in this area ( Figure 10) and after that normal packing was performed with Lucitone denture base acrylic. The lower complete denture was polymerized following the conventional technique. After that curing was performed, deflasking, trimming and polishing was carried out. After finishing and polishing, holes are placed in palate region and salt is removed with a syringe filled with water to make obturator in the bulb portion hollow. Following this holes were filled with auto polymerising resin (Self cure acrylic repair material, DPI).

The prosthesis was then inserted in the patients' mouth and the extensions, speech, occlusion and esthetics were evaluated. Necessary adjustments were done. Speech showed a definite improvement and patient was happy as there was a considerable improvement in esthetics. Patient was very cooperative during the whole procedure. Patient was followed up after 1 day, 1 week, 1 month. Necessary denture corrections were done in the follow up visits.

Figure 1:- Frontal view (Preoperative)

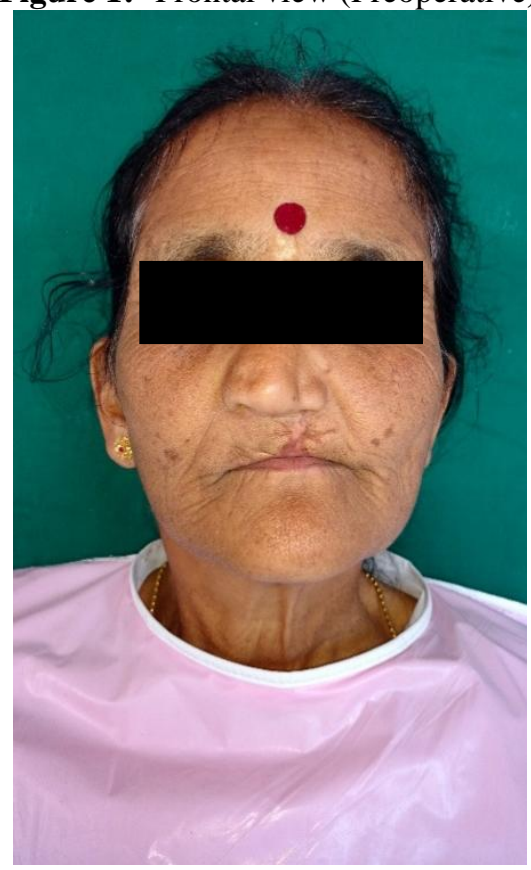


Figure 2:- Intraoral View

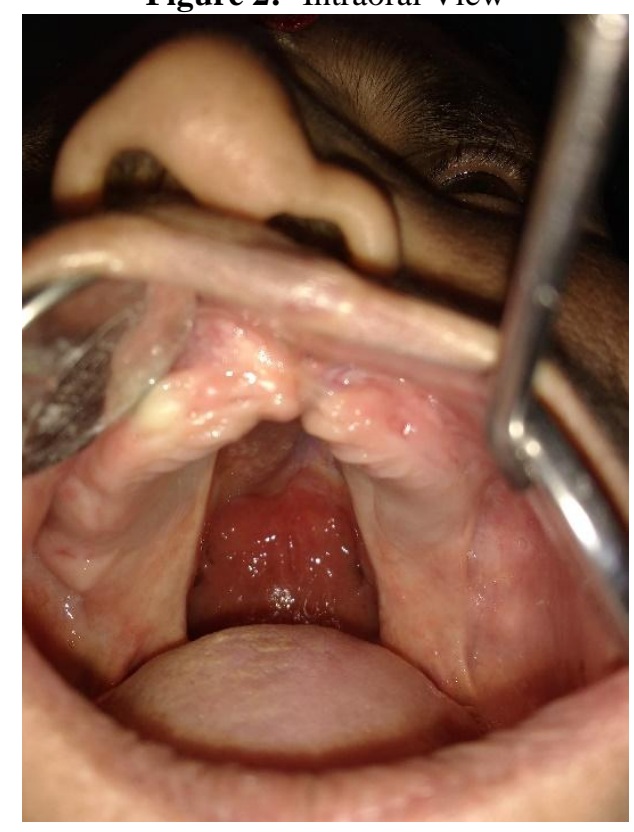

Figure 3:- Preliminary impression Of Maxillary arch with irreversible hydrocolloid

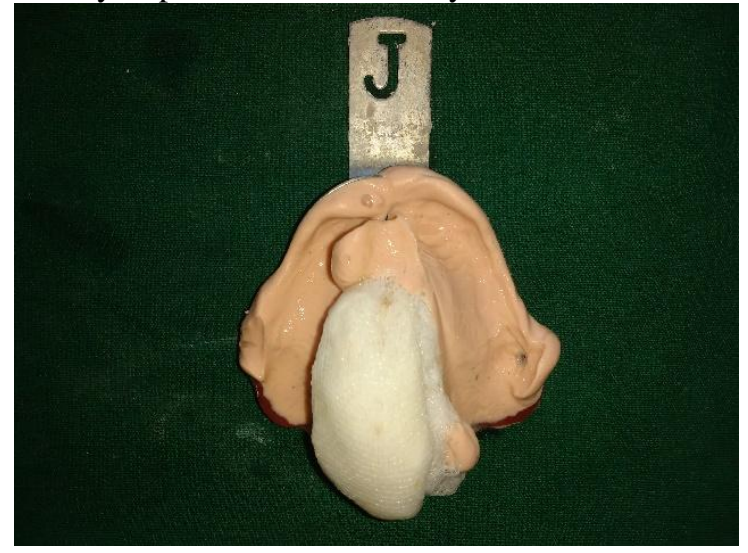

Figure 4:- Preliminary Impression of lower arch with impression compound

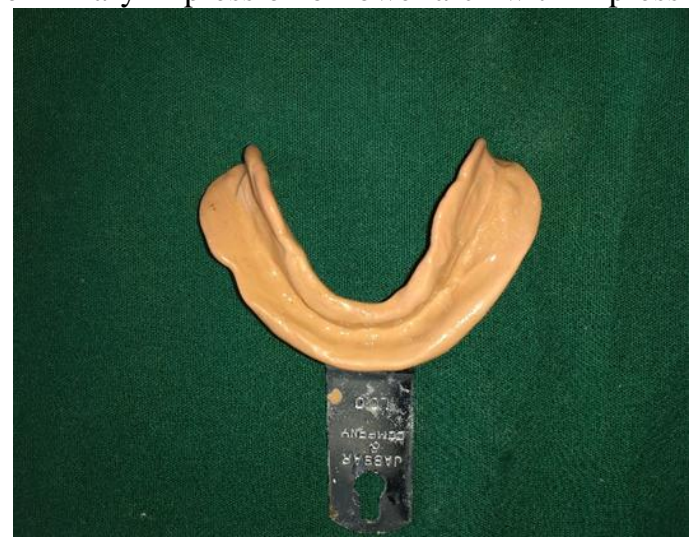


Figure 5:- U shaped wire loop attached to autopolymerising acrylic resin

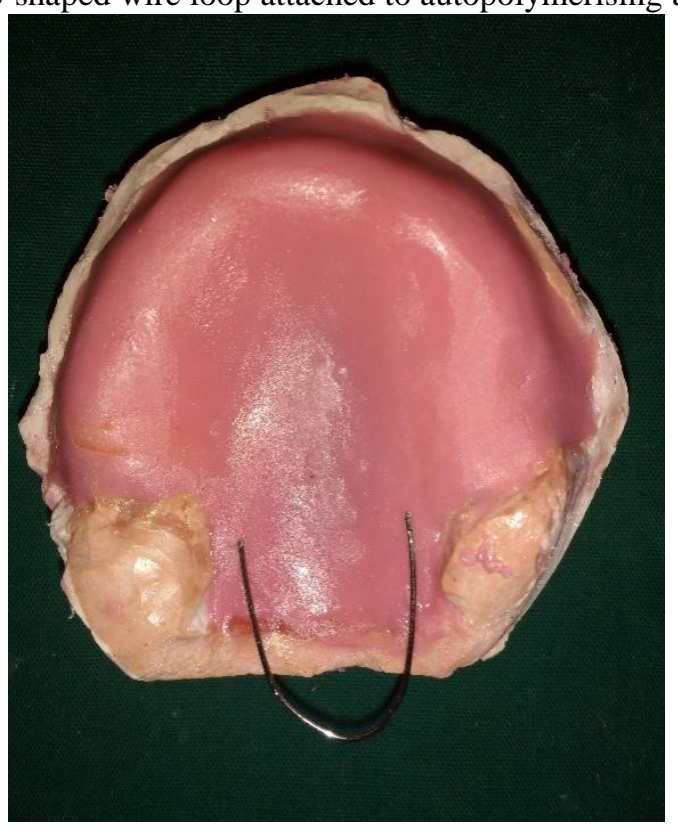

Figure 6:- Secondary impression with light body impression material

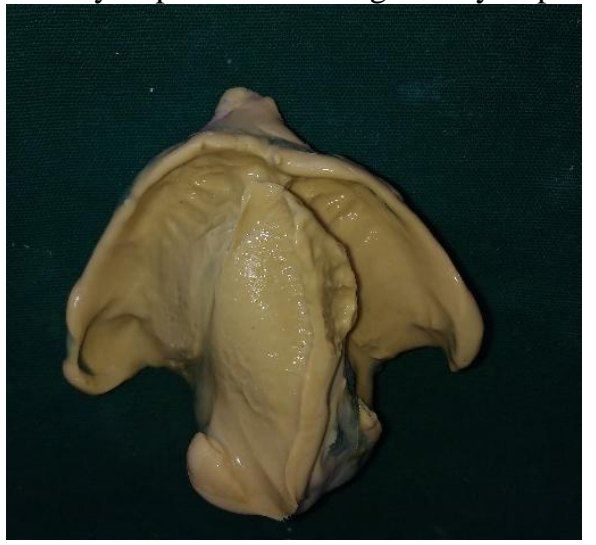

Figure 7:- Master Cast

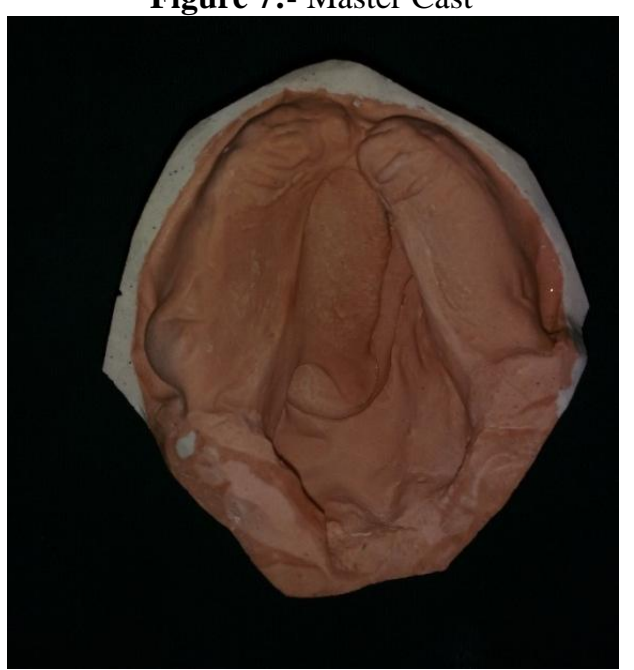


Figure 8:- Facebow Transfer

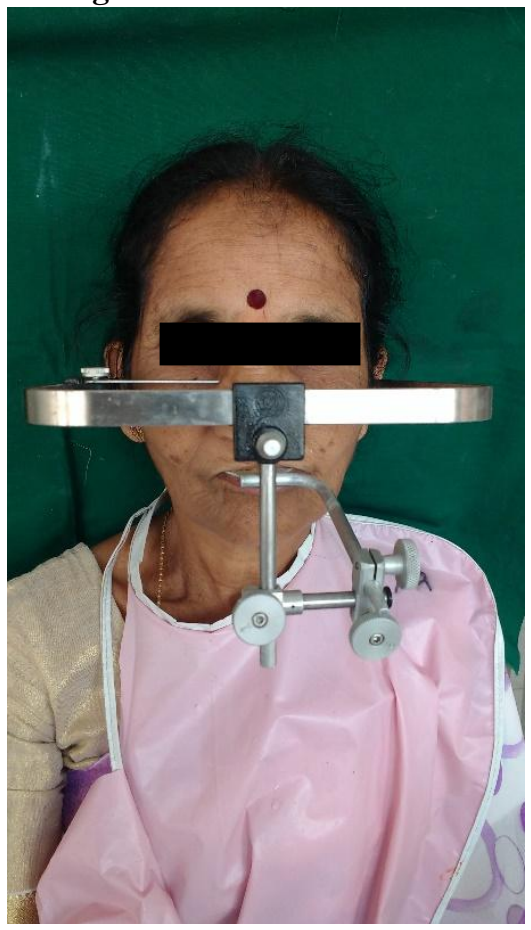

Figure 9:- Teeth arrangement

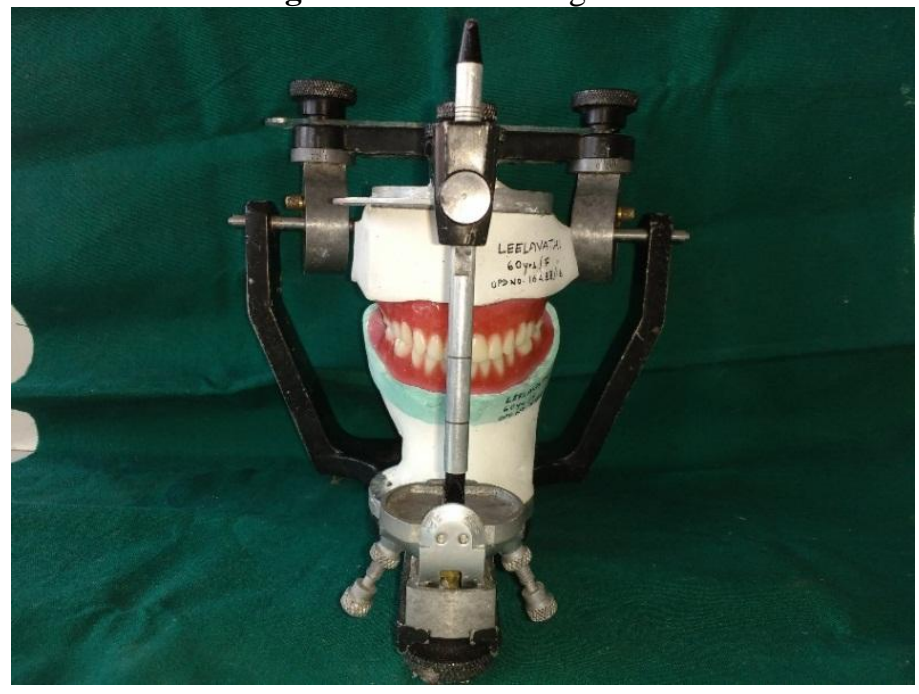


Figure 10:- Packing with table salt

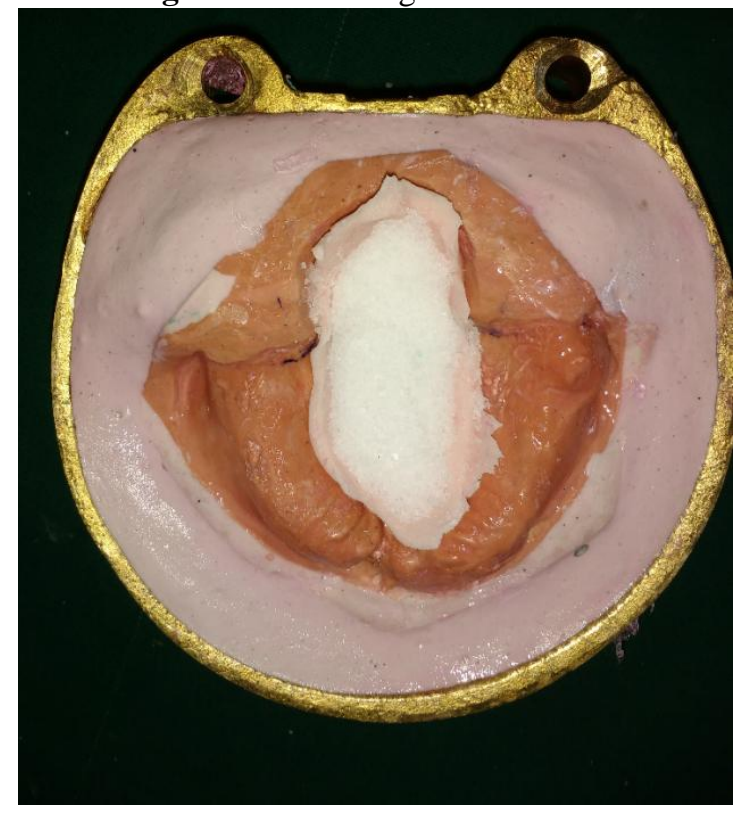

Figure 11:- Post Insertion

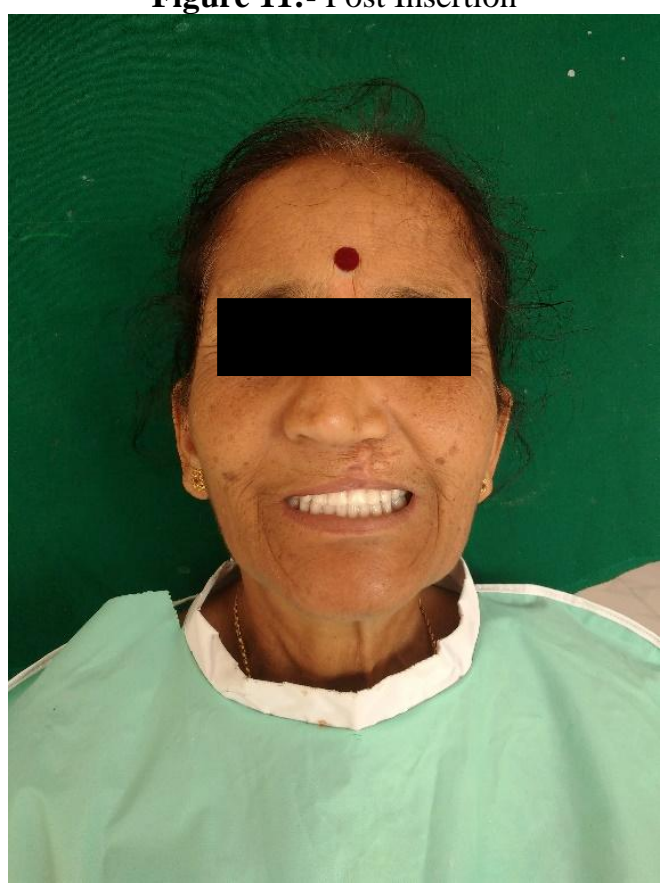




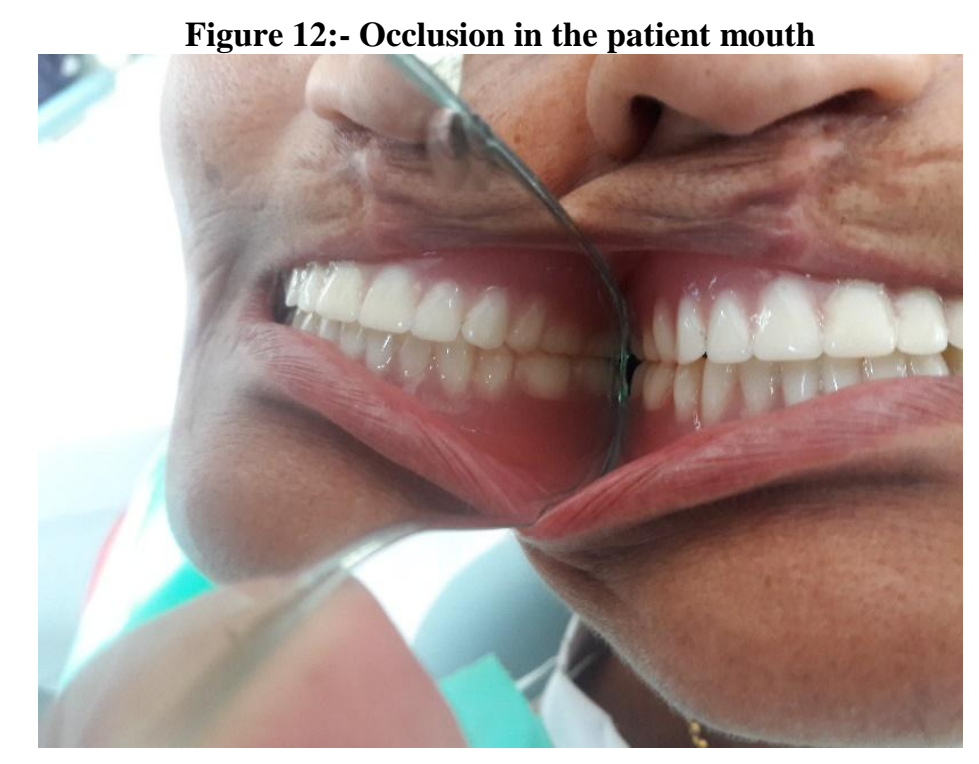

Figure 13:- Closed Hollow Bulb Maxillary Obturator and Lower denture

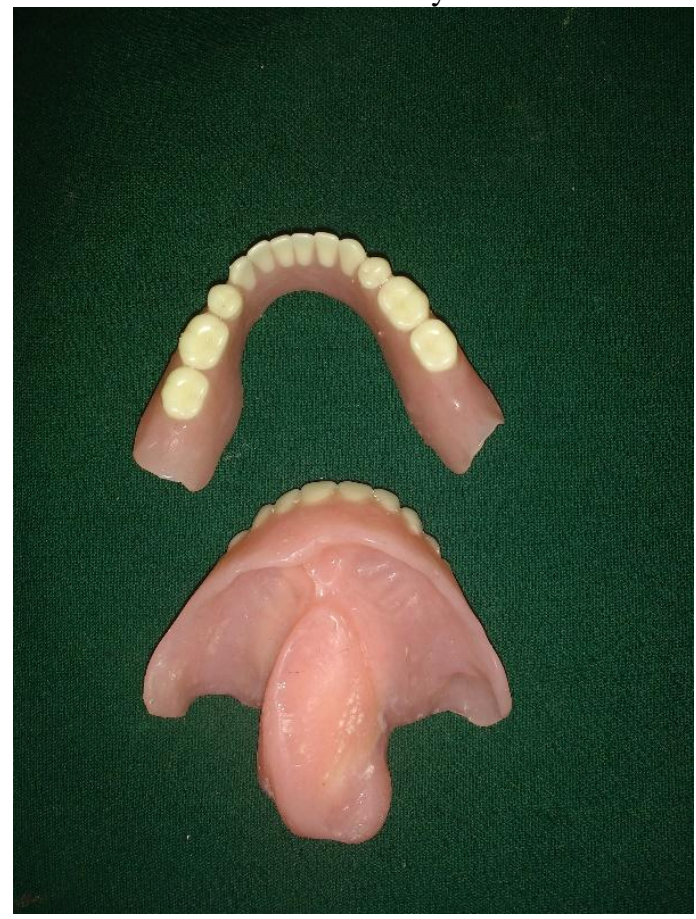

\section{Discussion:-}

Cleft palate rehabilitation involves essentially a multidisciplinary approach. The size and location of the defect are important considerations in selecting the method of rehabilitation. Small defects of the alveolar ridge and hard palate are easily closed surgically where as larger hard palate and/or soft palate defects are more amenable to prosthodontic obturation. ( Beumer 1996)

In the case presented here, early diagnosis and timely management i.e. sequential surgeries followed by orthodontic therapy would have led to a considerable decrease in the size of the defect. But unfortunately the congenital anomaly was left unattended. As the patient was not aware of the treatment resulting in the large size of the defect that dictated prosthodontic rehabilitation with a closed hollow bulb obturator. The literature has been reported various 
materials to be used for making hollow bulb obturator such as salt, ice, sugar, vinyl polysiloxane (Alva H 2012), plaster, polyurethane foam. (Agarwal P 2012).

The basic design of the obturator prosthesis used the available tissue bearing area extending into the defect to engage the undercuts to achieve maximum retention and stability. A hollow obturator allowed for the fabrication of a lightweight prosthesis that was readily tolerated by the patient while effectively extending into the defect where as a solid obturator in this case would be bulky and heavy that would jeopardize the supporting tissues. ( Brown KE1968,70). Hollow bulb provides advantages such as reduction in weight, increased retention, and making prosthesis comfortable. Closed hollow bulb obturators provide the advantage of preventing fluid and food accumulation, reducing airway space, and allow for maximum extension.

Hollow bulb prosthesis fabrication described in this article has advantages over the conventional procedures in that it is simple, time saving and cost effective.

\section{Conclusion:-}

The present case report describes the prosthodontic rehabilitation of a congenital maxillary defect in a patient, using definitive closed hollow bulb obturator, took care of the different domains of care, giving the patient an opportunity to live life as close to normal as possible. The instituted treatment has salved the functional, psychological, and esthetic needs of the patient. The use of hollow bulb obturator design improves the patient comfort by decreasing the weight of prosthesis.

\section{References:-}

1. Alva H, Prasad KD, Prasad AD. Prosthodontic rehabilitation of a patient with hollow bulb obturator: A case report. NUJHS 2012;2:60-2.

2. Agarwal P, Shah RJ. Case report: Two piece hollow bulb obturator for postsurgical partial maxillectomy defect in dentulous patient. Indian J Basic Appl Med Res 2012;2:438-42.

3. Beumer J, Curtis TA, Marunick MT. Maxillofacial rehabilitation, prosthodontic and surgical considerations. Ishiyaku Euro America: St. Louis; 1996. p. 399-402.

4. Brown KE. Peripheral considerations in improving obturator retention. J Prosthet Dent 1968;20:176-81.

5. Brown KE. Clinical considerations improving obturator treatment. J Prosthet Dent 1970;24:461-5.

6. Stewart KL, Rudd KD, Keubker WA. Clinical removable partial prosthodontics. 2nd ed. Ishiyaku Euro America Inc: St. Louis; 1997. p. 650. 